Flipped classroom and role-playing as active learning methods in the social work degree: randomized experimental study.

M José Gómez-Poyato ${ }^{a}$, Alejandra Aguilar-Latorre ${ }^{b^{*}}$, M Mar MartínezPerrochan $^{\mathrm{b}}$, Rosa Magallón-Botaya ${ }^{\mathrm{bc}}$, Bárbara Oliván-Blázquez ${ }^{\mathrm{a}, \mathrm{b}}$.

${ }^{a}$ Department of Psychology and Sociology. University of Zaragoza, Spain; ${ }^{b}$ Health Research Institute of Aragon, Spain; ${ }^{c}$ Department of Medicine, Psychiatry and Dermatology. University of Zaragoza, Spain.

* Corresponding author:

Alejandra Aguilar-Latorre.

Faculty of Social Science. Violante de Hungria 23. 50009 Zaragoza (Spain).

E-mail: alejandra31392@gmail.com

Telephone number: 0034685304966 /0034 976761000 ext 4547. 


\title{
Flipped classroom and role-playing as active learning methods in the social work degree: randomized experimental study.
}

\begin{abstract}
The inclusion of active learning methodologies in university degrees, such as Flipped Classroom and Role-playing require a higher degree of student involvement, greater dynamism in learning and increased content interaction. The main objective of this study is to evaluate the effectiveness of the Flipped Classroom and Role-Playing (FC+RP) methods as compared to traditional lecturer-based (LB) method, on the academic performance of social work students. It also aims to evaluate the effectiveness of the FC+RP in terms of satisfaction with the subject and the method used, and finally, with respect to the perceived difficulty of each theoretical topic. The hypotheses stating that students using FC+RP methods obtained a higher academic performance, and a lower perception of difficulty of the content as compared to students using the traditional LB method, were verified. However, it was not verified that students using FC+RP methods have greater satisfaction with the subject and the method used.
\end{abstract}

Keywords: Flipped classroom, role-playing, social work degree

\section{Introduction}

University training in social work encompasses multiple functions, such as teaching, research and practice, but it is constrained by the current limitations to social work approaches and methods. Increasing the impact of social work on the real world requires illuminating the complexities of reciprocal forces between humans and the environment (Balestrery, 2016). This means that the teaching methodologies used in the university courses must inspire reflection, critical thinking, encouragement of learning 
communities, etc. (Holmes, Tracy, Painter, Oestreich, \& Park, 2015; Sage \& Sele, 2015). Furthermore, universities are transferring the main role of the teaching-learning process from a model of knowledge transfer by teachers to a learning model that is based on student-centered competences.

Therefore, active learning methodologies requiring a higher degree of student involvement, greater dynamism in learning and increased content interaction (Graeff, 2010; Kober, 2015) should be used.

The Flipped Classroom (FC) is a form of active learning (Chen, Lui, \& Martinelli, 2017) that is consistent with a competency-based model (Basso-Aránguiz, Bravo-Molina, Castro-Riquelme, \& Moraga-Contreras, 2018). In the FC pedagogic method, learning is placed in the center of the training process, with the student playing a very active role, and with the teacher guiding and facilitating the learning process. This is mainly a reorganization of the activities according to the location where they are carried out; so, with this method, that which was traditionally taught in the classroom, will now be taught outside of it. Recent studies (Bergmann \& Sams, 2012; McDonald \& Smith, 2013) consider FC to be a pedagogical model that includes group and interactive learning activities within the classroom, since, this is where the acquisition process and theoretical knowledge is potentiated, and because it transfers individual learning work outside the classroom. Students engage in content learning prior to the class, thereby maximizing in-class time for active learning (Chen et al., 2018). The effectiveness of this pedagogic method has been examined in several fields, mainly in the Health Sciences (Betihavas, Bridgman, Kornhaber, \& Cross, 2016; Bonnes et al., 2017; Bossaer, Panus, Stewart, Hagemeier, \& George, 2016; Deprey, 2018; Geist, Larimore, Rawiszer, \& Sager, 2015; Heitz, Prusakowski, Willis, \& Franck, 2015; Moffett \& Mill, 2014; Njie-Carr et al., 2017; Pierce \& Fox, 2012; Presti, 2016; Tune, Sturek, \& Basile, 
2013; Wu, Chi, Wu, \& Kang, 2018), Physics and Chemistry (Baepler, Walker, \& Driessen, 2014), Engineering (Sahin, Cavlazoglu, \& Zeytuncu, 2015; Sein-Echaluce, Fidalgo-Blanco, Esteban-Escano, Garcia-Penalvo, Conde, 2018; Weinstein, 2015), etc. Studies on the effectiveness of FC in the social sciences (Albert \& Beatty, 2014; Roach, 2014), especially in the specific field of Social Work, however, are more scarce (Holmes et al., 2015; Sage \& Sele, 2015).

Another pedagogic method that is considered to be interactive (Norin, Norina, \& Pukharenko, 2018) is role-playing (RP). Role-playing is widely used, especially in the area of medical education and the teaching of communication skills (Xu et al., 2016) and social work students typically engage in role play with student colleagues to practice clinical intervention skills (Osborne, Benner, Sprague, \& Cleveland, 2016). It is a low-cost approach that is relatively easy to implement and permits trainees to experience the perspective of both the professional and the patient. Experiencing these multiple perspectives and the ambiguity of the partners involved in communication, helps to improve the understanding of the complexity of the professional interaction. (Bosse et al., 2010). Several studies have examined its effectivity, typically obtaining very positive results (Barnabè, Giorgino, Guercini, Bianciardi, \& Mezzatesta, 2018; Bosse et al., 2010; Fisher, Taylor, \& High, 2012; Rolland et al., 2018; Trail Ross, Otto, \& Stewart Helton, 2017; Westmoreland et al., 2018). In the training of social work graduate students in Spain, RP has been used along with other active learning methods, mainly for the learning of social and communication skills (Rosa, Navarro-Segura, \& López, 2014).

The FC method has resulted in greater academic achievement than the traditional lecturer-based (LB) learning and this has become increasingly more obvious over recent years (Chen et al., 2018), mainly due to the development of technological 
resources such as Google Drive, YouTube, Vimeo, Google Classroom, etc. (BassoAránguiz et al., 2018). Other studies have also used an FC intervention linked to roleplaying (Bas-Sarmiento, Fernández-Gutiérrez, Baena-Baños, \& Romero-Sánchez, 2017). This combination may be very effective, since some authors have noted that the most promising education models are those that use experiential learning styles, and the $\mathrm{RP}$ is considered to be an experiential learning style (Brunero, Lamont, \& Coates, 2010). Furthermore, RP has been widely used to improve clinical intervention skills (Osborne et al., 2016), and in this part of the course, these intervention skills are fundamental. And finally, the results of the study by Bas-Sarmiento et al. (2017), which was conducted using a combination of both techniques, were very positive for variables such as empathy and satisfaction with the learning.

Given the scarcity of studies on the social sciences and specifically, on social work, with regard to the effectiveness of the FC method and role-playing (RP), the main objective of this study is to evaluate the effectiveness of the Flipped Classroom and Role-Playing (FC+RP) methods as compared to the traditional lecturer-based (LB) method, on the academic performance of students. It also aims to evaluate the effectiveness of the FC+RP in terms of satisfaction with the subject and the method used, and finally, with respect to the perceived difficulty of each theoretical topic.

\section{Methodology}

\section{Design}

A randomized experimental study was conducted with two parallel groups. Randomization was carried out by class groups; one group of students (group 1) used an active teaching methodology based on FC+RP during the theoretical teaching hours, and another group of students (group 2) used an LB learning method. These pedagogic methods were used in group lectures of the social work degree program at the 
University of Zaragoza (Spain) during the 2017-2018 course year. This course consists of two parts: the first part is taught in the department of social psychology awareness and discusses group psychology, and the second is taught in the area of social work. This project was developed across six weeks and was implemented in three specific social work units. These units addressed the following content: 1) Introduction to social work with groups: history, concept and objectives; 2) Types of groups in social work, intervention techniques and methodology and professional roles; 3) Socio-educational, social support and task-centered or objective-centered groups.

\section{Participants and randomization}

Participants consisted of all of the students from group 1 and 2 of the morning schedule studying Social Work with Groups in the social work degree program and who consistently attended both the theoretical and practical course hours during the 20172018 course year. The sample size was 113 subjects, with 61 subjects engaging in FC+RP methods and 52 subjects receiving the LB method.

Randomization was carried out with a randomization computer program, developed by an independent study investigator.

\section{Interventions}

These interventions were carried out over six weeks during the months of April and May 2018. Students had 4 weekly teaching hours of this subject, two hours of theoretical content, one additional hour of practical content (in groups, having split the class in half), and one hour of supervised group work. The intervention was carried out in the theoretical content hours. Both FC+RP and LB methods were led by the same teacher, that is, the same teacher taught both groups and performed the same activities in both groups during the practical content hour and the supervised group work. This 
teacher has at least four years of experience teaching this subject, and also works as a social worker outside of the university.

In the intervention group, the FC + RP teaching methods were used. With these methods, prior to the theoretical classes, students had to work at home on the contents that would be taught later; RP was carried out during these classes. To ensure that the FC method was well received by the students, Rotellar and Cain's recommendations were followed in terms of the teacher and student's roles (Rotellar \& Cain, 2016, appendix 2). In the class schedule, the development of RP was proposed to create learning environments and situations that were simulated by the teacher and the students.

In developing the FC method, initial individualized activities were carried out (reading of theoretical content related to the teaching to be carried out in the upcoming theoretical class, questions and knowledge techniques). All of these, using the virtual teaching platform. These activities also provided the teacher with an idea of the students' capacities and skills, and served as the basis of preparation for the role playing.

Previously, the approaches and contents that were to be taught using the RP were discussed with the students, also planning the previous and subsequent activities, and creating a summary of the most important theoretical content, which was subsequently analyzed in order to determine if it had been understood.

After each module of theoretical content, students were divided into subgroups. In this first space, we work on the students' motivation to determine a real situation, which would be applicable to the studied contents. The necessary data were provided to carry out the representation, with two potential variants: 1) the teacher was the individual who assigned the roles or 2) the students were in charge of the role 
distribution. In both cases, the conflict, the characters, the situation and the context where the representation was developed must be determined. For the interpretation, each student is assigned a character with their characteristic role. One interesting possibility is that the character to be played by the students may have a different role, based on the student's personal character.

Students who are going to dramatize the chosen situation leave the classroom for approximately five minutes and the others, along with the teacher, agree on their role as observers, preparing a series of items to analyze. Afterwards, the interpretation takes place, which should not last for more than 45 minutes. A debate begins in which the different elements or actions that have taken place are analyzed, such as detection of the problem, feelings of each character, attitude toward the problem resolution, difficulties, etc. It should be highlighted that this method allows not only for an understanding of the importance of what is being learned but also, for the training of certain skills.

In the control group, a traditional LB learning method was used, consisting of the theoretical explanations of content by the classroom teacher. The students did not prepare themselves prior to the class, working on the content of the theoretical classes, and they did not engage in RP. During the hour of practical content and the hour of supervised group work, other activities were carried out. These activities consisted of the following: During the practical content hour, they engaged in a Storytelling activity throughout the subject, since each week, concepts were added and they were examined in greater detail in this storytelling activity, on a social work group. And during the supervised group work hour, brief weekly group work was carried out on the resolving of practical cases. These activities were carried out equally in both groups and by the same teacher. 
In order to ensure that both groups received the same teaching load throughout the 6 weeks of the teaching process and to make up for the time dedicated at home, 10 teaching hours of theoretical class were established for the group that followed the FC+RP methodology, since these students worked at home, and 12 teaching hours of theoretical class were established for the control group.

\section{Variables and measure instruments}

Main variable.

The outcome variable of the experimental study was academic performance, evaluated by the score obtained on a theoretical exam on the subject. This test consisted of 40 multiple-choice questions with 3 response options, taking chance into account (removing erroneous answers from the score). The quantitative rating ranges between 0 and 10, with a higher score implying a higher percentage of successful answers; and the qualitative ranges were: fail (between 0 and 4.9), pass (between 5.0 and 6.9), merit (between 7.0 and 8.9) and outstanding (between 9.0 and 10).

\section{Secondary variables}

The secondary variables were: student satisfaction with the subject and teaching method used, and perceived difficulty of each unit.

For assessment of student satisfaction, a seven-item questionnaire was used. These items were responded to using a Likert scale from 0 to 4 , with 0 : Not at all and 4: Very much. The questions were: Has the method used promoted new knowledge? Has it facilitated intense learning? Has it helped me to think more critically? Has it helped me to apply the theoretical content to practice? Has it helped me to apply the theoretical content to the evaluation? Has it helped me to better understand the concepts?; and I think it is a good teaching method. An open-ended question on their satisfaction was 
also included so that students could express their opinions openly and freely. Responses to this question have been analyzed qualitatively.

And finally, the perceived difficulty in understanding was assessed, using a scale of 0 to 10 that was collected at the end of each issue, with 0 being not difficult and 10 being extremely difficult.

Both the main variable and the satisfaction variable were collected after the 7 weeks of teaching. The perceived difficulty of each topic was collected at the end of each theoretical topic. The flowchart and the sample size of each variable is shown in figure 1 .

The following variables were also collected: gender, age, university entry score (between 5 and 14), number of subjects in which the students were enrolled and number of subjects passed. These variables were collected in order to determine if the groups of students were equivalent at the start of the study.

\section{Statistical analysis.}

An analysis of variable distribution was conducted in order to establish the type of statistics to be used; all quantitative variables had a non-normal distribution except the entry score and academic score in exam (academic performance). Therefore, we opted to use non-parametric statistics in the analysis of all quantitative variables except for the normal distribution variables. Subsequently, a comparison analysis of the groups was performed on the variables of gender, age, university entry score, number of ECTS credits enrolled in throughout the degree and number of credits passed, to determine if the groups were initially comparable at the start of the study. Chi-square and MannWhitney U or Student's T statistics were used, depending on whether the variable was qualitative or quantitative. To analyze the effectiveness of FC versus traditional LB learning, both groups were compared with respect to the main variable and secondary 
variables using the Mann-Whitney $U$ statistic and Student's $T$, based on their distribution. Finally, effect size was calculated using the $\mathrm{H}$ of Hedges with respect to the main variable.

Statistical analyses were performed with the SPSS 19.0 statistical software package, with $p$ values of less than 0.05 being considered significant.

\section{Ethical considerations}

This research project was funded by the University of Zaragoza (call for teaching innovation PIIDUZ_1_137), therefore, the university’s approval was granted. However, the University of Zaragoza has not intervened in the analysis or dissemination of the results. The study was performed in accordance with the Helsinki Declaration. All of the subjects completed an oral informed consent form, and their data were anonymized.

\section{Results}

Initially, a description of the variables of gender, age, university entry score and number of subjects passed was made. This description was made by taking the global sample into account and in groups (to ensure comparability, analyzing the p value). As shown in Table 1, the participant profile tends to be female (88.5\%), with an average age of 20.5 years (SD: 3.37), entering the degree program with an average score of 8.35 (Dt: 1.51$)$ and has, thus far, passed an average of 13.88 subjects. Table 2 shows that no significant differences exist between the two groups with regard to the variables collected at the beginning of the study. In both tables, the values of the mean and standard deviation, median, Q25 and Q27 are shown.

Table 3 shows the results of the experimental study. Groups were compared with respect to the main variable, academic performance, which was collected by the quantitative qualification obtained on the exam. There was a significant difference in 
the qualitative qualifications in the exam, since the group using the FC + RP methods obtained a higher average score on the exam, although no differences were found in the qualitative qualifications. Exam attendance was similar in both groups, since in the FC

+ RP group, 3 people did not attend and in the LB group, 2 people did not take the exam. The effect size was calculated for the main variable (academic performance) and the Hedges g was 0.992. As for the comparison of the groups with regard to the satisfaction variable, the results obtained show that there were no significant differences in the satisfaction of both groups of students, obtaining a good general assessment in both groups. And finally, regarding the perceived difficulty of the subjects, significant differences were found between both groups, with less difficulty being found for the FC $+\mathrm{RP}$ group.

Regarding the qualitative assessment of their satisfaction, the FC + RP group highlighted a large number of positive comments on the RP, its usefulness, and its benefit for future work situations, and the dynamism of the classes.

\section{Discussion}

The hypotheses stating that students who develop FC+RP methods obtained a higher academic performance (quantitative), and a lower perception of difficulty of the content with respect to the students who develop a traditional LB method, were verified. However, it was not verified that the students who develop an FC+RP intervention obtain greater satisfaction with the subject and the method used.

Regarding the academic performance variable, the results obtained coincide with the existing bibliography. Studies analyzing the effectiveness of the FC method agree that it is more effective (Chen et al., 2018). Studies analyzing the effectiveness of RP also establish that it is more effective (Barnabè et al., 2018; Bosse et al., 2010; Fisher et al., 2012; Rolland et al., 2018; Trail Ross et al., 2017; Westmoreland et al., 2018). 
However, to the best of our knowledge, there are no studies evaluating the effectiveness of FC and RP with regards to the academic performance, so it is not possible to evaluate the effectiveness of both methods together, as compared to other studies. It should be noted that the qualification obtained in the exam assesses knowledge change according to Kirkpatrick's level 2 measurement (learning) (Kirkpatrick \& Kirkpatrick, 1959); however, if we take into account the acquisition of competences, the use of the FC + RP methods is quite appropriate, since competencies are translated into observable behaviors (Berrocal Berrocal \& Pereda Marín, 2001), and RP facilitates the acquisition of these behaviors when practiced in learning. A competence is an individual's underlying characteristic (i.e. knowledge, skills and aptitudes), causally related to good or excellent performance in a specific position and organization (Boyatzis, 1982; Forrier, Sels, \& Stynen, 2009). Competency-based learning is a response to the needs of our contemporary society based on the different professional areas and the different activity areas.

As for the satisfaction variable and the positive feelings felt with regards to the teaching method, in several research studies, both the FC and the RP have been found to separately obtain better scores as compared to other methods (Burnham \& Mascenik, 2018; McLaughlin et al., 2014; Presti, 2016; Soler Sánchez MI, Meseguer de Pedro M, 2016), and also in combination of both (Bas-Sarmiento et al., 2017) . However, in our study, satisfaction does not differ statistically between the groups of students. In our study, this may be due to the fact that in both groups, high levels of satisfaction are obtained (scores exceeding 3 out of 4 points on all the items), since according to student feedback, they generally consider that the Subject of Social Work with Groups content is interesting and they are highly motivated with regards to the same, as well as its usefulness for their professional future (Moyse Steinberg, 1993). 
Regarding the perception of difficulty, the group using the FC + RP methods perceived significantly less difficulty in three out of four subjects, as compared to the LB group. This data coincides with the facilitation of the learning implied by FC and RP (Barnabè et al., 2018; Bosse et al., 2010; Fisher et al., 2012; Rolland et al., 2018; Trail Ross et al., 2017; Westmoreland et al., 2018).

And finally, this study has also revealed that RP permits students to discover their abilities and the areas where they may have been less prepared, and in areas that need to be strengthened in their learning process. This may give them a greater sense of responsibility in their learning process and allow them to advance in meta-learning, since they are not only the "actors" but also the observer-participants in the process.

This study has certain strengths and limitations. Its strengths include its contribution to evidence for the use of this active learning methodology in the teaching of social sciences, since limited evidence currently exists in these disciplines, as well as its methodological rigor, since a randomized experimental study methodology has been used with two groups in parallel. This methodology provides great scientific evidence when controlling for all biases (Manterola \& Zavando, 2009). On the other hand, one limitation of this study lies in the collection of the satisfaction variable and perceived difficulty, since in the experimental methodology, it is recommended that the evaluator be blind to the assignment, so as to avoid influencing the assessment, especially in cases of hetero-administration. Here, it is considered that no bias occurred, since even though the evaluator was not blind to the assignment, he/she could not interfere with the results, since the variables were collected in a self-administered test.

\section{Conclusions}


The FC + RP methods have been found to be more effective tools as compared to LB in university social work education, based on the academic performance that was quantitatively evaluated and the perception of difficulty of the content. However, no significant differences were found with respect to satisfaction with the subject and the method used. The qualitative evaluation of satisfaction highlighted the perception of the utility of FC + RP, and its potential benefits for future work situations.

\section{Acknowledgements}

We wish to thank the University of Zaragoza, (Spain); Research Group B21_R17 of the Department of Research, Innovation and University of the Government of Aragon (Spain); and Feder Funds "Another way to make Europe" for their support in the development of the study

\section{Funding}

This work was supported by the University of Zaragoza (call for teaching innovation PIIDUZ_1_137).

\section{Conflict of interest}

The authors have no declared conflicts of interest.

\section{Data availability statement}

The data supporting the findings of this study are available upon request from the last author.

\section{References}

Albert, M., \& Beatty, B. J. (2014). Flipping the Classroom Applications to Curriculum Redesign for an Introduction to Management Course: Impact on Grades. Journal of Education for Business, 89(8), 419-424.

https://doi.org/10.1080/08832323.2014.929559 
Baepler, P., Walker, J. D., \& Driessen, M. (2014). It's not about seat time: Blending, flipping, and efficiency in active learning classrooms. Computers \& Education, 78, 227-236. https://doi.org/10.1016/j.compedu.2014.06.006

Balestrery, J. E. (2016). Social Work Education without Walls: Ethnography as a Lens for Transformative Learning. Social Work Education, 35(6), 615-631. https://doi.org/10.1080/02615479.2016.1151490

Barnabè, F., Giorgino, M. C., Guercini, J., Bianciardi, C., \& Mezzatesta, V. (2018). Management simulations for Lean healthcare: exploiting the potentials of roleplaying. Journal of Health Organization and Management, 32(2), 298-320. https://doi.org/10.1108/JHOM-07-2017-0191

Bas-Sarmiento, P., Fernández-Gutiérrez, M., Baena-Baños, M., \& Romero-Sánchez, J. M. (2017). Efficacy of empathy training in nursing students: A quasi-experimental study. Nurse Education Today, 59, 59-65. https://doi.org/10.1016/j.nedt.2017.08.012

Basso-Aránguiz, M., Bravo-Molina, M., Castro-Riquelme, A., \& Moraga-Contreras, C. (2018). Propuesta de modelo tecnológico para Flipped Classroom (T-FliC) en educación superior. Revista Electrónica Educare, 22(2), 1. https://doi.org/10.15359/ree.22-2.2

Bergmann, J., \& Sams, A. (2012). Flip your classroom : reach every student in every class every day. International Society for Technology in Education. Retrieved from https://www.iste.org/resources/product?ID=2285

Berrocal Berrocal, F., \& Pereda Marín, S. (2001). Formación y gestión del conocimiento. Revista Complutense de Educación, 12, 639-656.

Betihavas, V., Bridgman, H., Kornhaber, R., \& Cross, M. (2016). The evidence for “flipping out”: A systematic review of the flipped classroom in nursing education. 
Nurse Education Today, 38, 15-21. https://doi.org/10.1016/j.nedt.2015.12.010

Bonnes, S. L., Ratelle, J. T., Halvorsen, A. J., Carter, K. J., Hafdahl, L. T., Wang, A. T., ... Wittich, C. M. (2017). Flipping the Quality Improvement Classroom in Residency Education. Academic Medicine : Journal of the Association of American Medical Colleges, 92(1), 101-107. https://doi.org/10.1097/ACM.0000000000001412

Bossaer, J. B., Panus, P., Stewart, D. W., Hagemeier, N. E., \& George, J. (2016). Student Performance in a Pharmacotherapy Oncology Module Before and After Flipping the Classroom. American Journal of Pharmaceutical Education, 80(2), 31. https://doi.org/10.5688/ajpe80231

Bosse, H. M., Nickel, M., Huwendiek, S., Jünger, J., Schultz, J. H., \& Nikendei, C. (2010). Peer role-play and standardised patients in communication training: a comparative study on the student perspective on acceptability, realism, and perceived effect. BMC Medical Education, 10, 27. https://doi.org/10.1186/1472$6920-10-27$

Boyatzis, R. E. (1982). The competent manager : a model for effective performance. Wiley. Retrieved from https://books.google.es/books?hl=es\&lr=\&id=KmFR7BnLdCoC\&oi=fnd\&pg=PR 11\&dq=Boyatzis,+R.+(1982).+The+competent+manager:+a+model+for+effective +performance\&ots=wv6IWnNsXA\&sig=BxpatJQIIRXnJJOQbqVFYvoEFo\#v=onepage\&q=Boyatzis\%2C R. (1982). The competent manager

Brunero, S., Lamont, S., \& Coates, M. (2010). A review of empathy education in nursing. Nursing Inquiry, 17(1), 65-74. https://doi.org/10.1111/j.14401800.2009.00482.x

Burnham, K. D., \& Mascenik, J. (2018). Comparison of student performance and 
perceptions of a traditional lecture course versus an inverted classroom format for clinical microbiology. Journal of Chiropractic Education, 32(2), 90-97. https://doi.org/10.7899/JCE-17-21

Chen, F., Lui, A. M., \& Martinelli, S. M. (2017). A systematic review of the effectiveness of flipped classrooms in medical education. Medical Education, 51(6), 585-597. https://doi.org/10.1111/medu.13272

Chen, K.-S., Monrouxe, L., Lu, Y.-H., Jenq, C.-C., Chang, Y.-J., Chang, Y.-C., \& Chai, P. Y.-C. (2018). Academic outcomes of flipped classroom learning: a metaanalysis. Medical Education, 52(9), 910-924. https://doi.org/10.1111/medu.13616 Deprey, S. M. (2018). Outcomes of Flipped Classroom Instruction in an Entry-Level Physical Therapy Course. Journal of Physical Therapy Education, 32(3), 289-294. https://doi.org/10.1097/JTE.0000000000000035

Fisher, M. J., Taylor, E. A., \& High, P. L. (2012). Parent-Nursing Student Communication Practice: Role-Play and Learning Outcomes. Journal of Nursing Education, 51(2), 115-119. https://doi.org/10.3928/01484834-20111216-04

Forrier, A., Sels, L., \& Stynen, D. (2009). Career mobility at the intersection between agent and structure: A conceptual model. Journal of Occupational and Organizational Psychology, 82(4), 739-759. https://doi.org/10.1348/096317909X470933

Geist, M. J., Larimore, D., Rawiszer, H., \& Sager, A. W. Al. (2015). Flipped Versus Traditional Instruction and Achievement in a Baccalaureate Nursing Pharmacology Course. Nursing Education Perspectives, 36(2), 114-115. https://doi.org/10.5480/13-1292

Graeff, T. R. (2010). Strategic Teaching for Active Learning. Marketing Education Review, 20(3), 265-278. https://doi.org/10.2753/MER1052-8008200307 
Heitz, C., Prusakowski, M., Willis, G., \& Franck, C. (2015). Does the Concept of the \&quot;Flipped Classroom\&quot; Extend to the Emergency Medicine Clinical Clerkship? The Western Journal of Emergency Medicine, 16(6), 851-855. https://doi.org/10.5811/westjem.2015.9.27256

Holmes, M. R., Tracy, E. M., Painter, L. L., Oestreich, T., \& Park, H. (2015). Moving from Flipcharts to the Flipped Classroom: Using Technology Driven Teaching Methods to Promote Active Learning in Foundation and Advanced Masters Social Work Courses. Clinical Social Work Journal, 43(2), 215-224. https://doi.org/10.1007/s10615-015-0521-x

Kirkpatrick Donal L, \& Kirkpatrick, J. D. (1959). Evaluating trainning programs. The four levels. Journal of the American Society of Training Directors, 13, 3-9.

Kober, L. (2015). Reaching Students: What Research Says About Effective Instruction in Undergraduate Science and Engineering. Washington, D.C.: National Academies Press. https://doi.org/10.17226/18687

Manterola, C., \& Zavando, D. (2009). Cómo interpretar los Niveles de Evidencia en los diferentes escenarios clínicos. Revista Chilena de Cirugía, 61(6), 582-595. https://doi.org/10.4067/S0718-40262009000600017

McDonald, K., \& Smith, C. M. (2013). The Flipped Classroom for Professional Development: Part I. Benefits and Strategies. The Journal of Continuing Education in Nursing, 44(10), 437-438. https://doi.org/10.3928/00220124-20130925-19

McLaughlin, J. E., Roth, M. T., Glatt, D. M., Gharkholonarehe, N., Davidson, C. A., Griffin, L. M., ... Mumper, R. J. (2014). The flipped classroom: a course redesign to foster learning and engagement in a health professions school. Academic Medicine: Journal of the Association of American Medical Colleges, 89(2), 236243. https://doi.org/10.1097/ACM.0000000000000086 
Moffett, J., \& Mill, A. C. (2014). Evaluation of the flipped classroom approach in a veterinary professional skills course. Advances in Medical Education and Practice, 5, 415-425. https://doi.org/10.2147/AMEP.S70160

Moyse Steinberg, D. (1993). Some Findings from a Study on the Impact of Group Work Education on Social Work Practitioners’ Work with Groups. Social Work With Groups, 16(3), 23-39. https://doi.org/10.1300/J009v16n03_03

Njie-Carr, V. P. S., Ludeman, E., Lee, M. C., Dordunoo, D., Trocky, N. M., \& Jenkins, L. S. (2017). An Integrative Review of Flipped Classroom Teaching Models in Nursing Education. Journal of Professional Nursing : Official Journal of the American Association of Colleges of Nursing, 33(2), 133-144. https://doi.org/10.1016/j.profnurs.2016.07.001

Norin, V. A., Norina, N. V., \& Pukharenko, Y. V. (2018). Interactive methods of teaching at Russian engineering universities. Education and Information Technologies, 23(6), 2801-2820. https://doi.org/10.1007/s10639-018-9742-2

Osborne, V. A., Benner, K., Sprague, D. J., \& Cleveland, I. N. (2016). Simulating Real Life: Enhancing Social Work Education on Alcohol Screening and Brief Intervention. Journal of Social Work Education, 52(3), 337-346. https://doi.org/10.1080/10437797.2016.1174629

Pierce, R., \& Fox, J. (2012). Vodcasts and active-learning exercises in a "flipped classroom" model of a renal pharmacotherapy module. American Journal of Pharmaceutical Education, 76(10), 196. https://doi.org/10.5688/ajpe7610196

Presti, C. R. (2016). The Flipped Learning Approach in Nursing Education: A Literature Review. The Journal of Nursing Education, 55(5), 252-257. https://doi.org/10.3928/01484834-20160414-03

Roach, T. (2014). Student perceptions toward flipped learning: New methods to 
increase interaction and active learning in economics. International Review of Economics Education, 17, 74-84. https://doi.org/10.1016/J.IREE.2014.08.003 Rolland, B., Fovet, T., Poissy, J., Eichholtzer, C., Lesage, M., Thomas, P., \& Jourdain, M. (2018). Evaluation by undergraduate medical students of a role-playing training program on the management of acute states of agitation. L'Encéphale, 44(2), 101105. https://doi.org/10.1016/j.encep.2017.09.009

Rosa, G., Navarro-Segura, L., \& López, P. (2014). Learning Process of Social Skills at University Level. Analysis of a Training Experience in Social Education and Social Work Degrees. Formación Universitaria, 7(4), 25-38. https://doi.org/10.4067/S0718-50062014000400004

Rotellar, C., \& Cain, J. (2016). Research, Perspectives, and Recommendations on Implementing the Flipped Classroom. American Journal of Pharmaceutical Education, 80(2), 34. https://doi.org/10.5688/ajpe80234

Sage, M., \& Sele, P. (2015). Reflective Journaling as a Flipped Classroom Technique to Increase Reading and Participation with Social Work Students. Journal of Social Work Education, 51(4), 668-681. https://doi.org/10.1080/10437797.2015.1076274

Sahin, A., Cavlazoglu, B., \& Zeytuncu, Y. E. (2015). Flipping a College Calculus Course: A Case Study. Journal of Educational Technology \& Society. International Forum of Educational Technology \& Society. https://doi.org/10.2307/jeductechsoci.18.3.142

Sein-Echaluce, ML; Fidalgo-Blanco, A ; Esteban-Escano, J ; Garcia-Penalvo, FJ ; Conde, M. (2018). Using Learning Analytics to Detect Authentic Leadership Characteristics in Engineering Students. IInternational Journal of Engineering Education, 34(3), 851-864. Retrieved from http://apps.webofknowledge.com.cuarzo.unizar.es:9090/full_record.do?product=W 
OS\&search_mode=GeneralSearch\&qid=39\&SID=D63BWMzLgncrDd1UJxv\&pa ge $=1 \&$ doc $=3$

Soler Sánchez MI, Meseguer de Pedro M, G. I. M. (2016). Psychometric properties of the Spanish version of the 10-item scale of resilience of Connor-Davidson (CDRISC 10) in a multi- occupational sample. Rev Latinoam Psicol, 48(3), 159-166.

Trail Ross, M. E., Otto, D. A., \& Stewart Helton, A. (2017). Benefits of Simulation and Role-Playing to Teach Performance of Functional Assessments. Nursing Education Perspectives, 38(1), 47-48. https://doi.org/10.1097/01.NEP.0000000000000095

Tune, J. D., Sturek, M., \& Basile, D. P. (2013). Flipped classroom model improves graduate student performance in cardiovascular, respiratory, and renal physiology. Advances in Physiology Education, 37(4), 316-320.

https://doi.org/10.1152/advan.00091.2013

Weinstein, R. D. (2015). Improved performance via the inverted classroom. Chemical Engineering Education, 49(3), 141-148.

Westmoreland, K. D., Banda, F. M., Steenhoff, A. P., Lowenthal, E. D., Isaksson, E., \& Fassl, B. A. (2018). A standardized low-cost peer role-playing training intervention improves medical student competency in communicating bad news to patients in Botswana. Palliative and Supportive Care, 1-6. https://doi.org/10.1017/S1478951518000627

Wu, J.-C., Chi, S.-C., Wu, C.-C., \& Kang, Y.-N. (2018). Helps from flipped classroom in learning suturing skill: The medical students’ perspective. PLOS ONE, 13(10), e0204698. https://doi.org/10.1371/journal.pone.0204698

Xu, X.-F., Wang, Y., Wang, Y.-Y., Song, M., Xiao, W.-G., \& Bai, Y. (2016). Roleplaying is an effective instructional strategy for genetic counseling training: an investigation and comparative study. BMC Medical Education, 16(1), 235. 
https://doi.org/10.1186/s12909-016-0756-4 
Table 1. Type your title here. Obtain permission and include the acknowledgement required by the copyright holder if a table is being reproduced from another source.

\section{TABLES}

Table 1: Description of the variables of sex, age, university entry score, number of subjects in which students had enrolled and number of subjects passed.

\begin{tabular}{|l|l|l|l|l|}
\hline \multirow{2}{*}{ VARIABLES } & \multicolumn{4}{|l|}{ SAMPLE N=110 } \\
\cline { 2 - 5 } & Mean (DT) & Median & Q25 & Q75 \\
\hline Age & $20.57(3.37)$ & 20 & 19 & 21 \\
\hline University entry score & $8.35(1.51)$ & 8.0 & 7.30 & 9.32 \\
\hline Enrolled subject & $15.18(1.92)$ & 15 & 15 & 15 \\
\hline Passed subject & $13.88(1.98)$ & 14 & 13 & 15 \\
\hline Sex (\% women) & $88.5 \%$ & \multicolumn{4}{|l}{} \\
\hline
\end{tabular}

Table 2: Basal comparison between both groups for the variables of sex, age, university entry score, number of subjects in which the students had enrolled and number of subjects passed.

\begin{tabular}{|c|c|c|c|c|c|c|c|c|c|}
\hline \multirow[t]{2}{*}{ VARIABLES } & \multicolumn{4}{|c|}{ FC+RP GROUP N=61 } & \multicolumn{4}{|c|}{ LB GROUP N=52 } & \multirow{2}{*}{$\begin{array}{l}\text { pvalu } \\
\text { e }\end{array}$} \\
\hline & $\begin{array}{l}\text { Mean } \\
\text { (DT) }\end{array}$ & $\begin{array}{l}\text { Media } \\
\mathrm{n}\end{array}$ & Q25 & Q75 & $\begin{array}{l}\text { Mean } \\
\text { (DT) }\end{array}$ & $\begin{array}{l}\text { Med } \\
\text { ian }\end{array}$ & Q25 & Q75 & \\
\hline Age (mean) & $\begin{array}{l}20.87 \\
(4.46)\end{array}$ & 20 & 19 & 21 & $\begin{array}{l}20.27 \\
(1.70)\end{array}$ & 20 & 19 & 21 & 0.931 \\
\hline $\begin{array}{l}\text { University entry } \\
\text { score }\end{array}$ & $\begin{array}{l}8.66 \\
(1.66)\end{array}$ & 7.38 & 8.02 & 9.90 & $\begin{array}{l}8.14 \\
(1.45)\end{array}$ & 8.0 & 7.09 & 9.07 & 0.148 \\
\hline Enrolled subjects & $\begin{array}{l}15.26 \\
(1.75)\end{array}$ & 15 & 15 & 15 & $\begin{array}{l}15.10 \\
(2.13)\end{array}$ & 15 & 15 & 15 & 0.236 \\
\hline Subjects passed & $\begin{array}{l}14.28 \\
(1.59)\end{array}$ & 14 & 13 & 15 & $\begin{array}{l}13.41 \\
(2.28) \\
\end{array}$ & 14 & 13 & 15 & 0.132 \\
\hline Sex (\% women) & \multicolumn{4}{|l|}{$90.2 \%$} & \multicolumn{4}{|l|}{$86.5 \%$} & 0.547 \\
\hline
\end{tabular}

The Mann-Whitney U statistic was used when variables presented a non-normal distribution except for the variable university entry score, which had a normal distribution, and $\mathrm{T}$ student was used. In the analysis of the gender variable, the chisquare statistic was used. 
Table 3: Comparison between the FC + RP Group and LB group in the academic performance outcome variable (quantitative and qualitative), satisfaction (quantitative) and perceived difficulty.

\begin{tabular}{|c|c|c|c|c|c|c|c|c|c|}
\hline \multirow[t]{2}{*}{ VARIABLES } & \multicolumn{4}{|c|}{ FC+RP GROUP } & \multicolumn{4}{|l|}{ LB GROUP } & \multirow[t]{2}{*}{ pvalue } \\
\hline & $\begin{array}{l}\text { Mean } \\
\text { (DT) }\end{array}$ & $\begin{array}{l}\text { Media } \\
\mathrm{n}\end{array}$ & Q25 & Q75 & Mean (DT) & Median & Q25 & Q75 & \\
\hline Academic performance (quantitative score) & $7.22(1.50)$ & 7.30 & 6.50 & 8,00 & $6,75(1,31)$ & 6,90 & 6,00 & 7,50 & 0,041 \\
\hline $\begin{array}{l}\text { Satisfaction (quantitative) } \\
\text { has promoted new knowledge } \\
\text { has facilitated intense learning } \\
\text { help me to think more critically } \\
\text { help to apply the theoretical content to } \\
\text { practice } \\
\text { help to apply the theoretical content to } \\
\text { evaluation } \\
\text { help to better understand the concepts } \\
\text { I think it is a good teaching method }\end{array}$ & $\begin{array}{l}3.18(0.67) \\
3.21(0.64) \\
3.12(0.76) \\
3.59(0.55) \\
3.29(0.67) \\
3.44(0.61) \\
3.53(0.61)\end{array}$ & $\begin{array}{l}3.0 \\
3.0 \\
3.0 \\
4.0 \\
3.0 \\
3.5 \\
4.0\end{array}$ & $\begin{array}{l}3.0 \\
3.0 \\
3.0 \\
3.0 \\
3.0 \\
3.0 \\
3.0\end{array}$ & $\begin{array}{l}4.0 \\
4.0 \\
4.0 \\
4.0 \\
4.0 \\
4.0 \\
4.0\end{array}$ & $\begin{array}{l}3.26(0.61) \\
3.00(0.81) \\
2.74(0.93) \\
3.29(0.79) \\
3.12(0.80) \\
3.26(0.75) \\
3.12(0.97)\end{array}$ & $\begin{array}{l}3.0 \\
3.0 \\
3.0 \\
3.0 \\
3.0 \\
3.0 \\
3.0\end{array}$ & $\begin{array}{l}3.0 \\
2.0 \\
2.0 \\
3.0 \\
3.0 \\
3.0 \\
3.0\end{array}$ & $\begin{array}{l}4.0 \\
4.0 \\
3.25 \\
4.0 \\
4.0 \\
4.0 \\
4.0\end{array}$ & $\begin{array}{l}0.607 \\
0.319 \\
0.077 \\
0.132 \\
0.408 \\
0.368 \\
0.072\end{array}$ \\
\hline $\begin{array}{l}\text { Perceived difficulty } \\
\text { Topic } 1 \\
\text { Topic } 2 \\
\text { Topic } 3 \\
\text { Topic } 4 \\
\end{array}$ & $\begin{array}{l}6.00(1.55) \\
5.57(1.50) \\
5.45(1.72) \\
6.00(1.80)\end{array}$ & $\begin{array}{l}7.0 \\
5.5 \\
6.0 \\
6.0\end{array}$ & $\begin{array}{l}5.0 \\
5.0 \\
4.0 \\
4.5\end{array}$ & $\begin{array}{l}7.0 \\
7.0 \\
7.0 \\
7.0 \\
\end{array}$ & $\begin{array}{l}6.97(1.24) \\
6.74(1.40) \\
6.74(1.22) \\
6.29(1.75) \\
\end{array}$ & $\begin{array}{l}7.0 \\
7.0 \\
7.0 \\
7.0 \\
\end{array}$ & $\begin{array}{l}6.0 \\
6.0 \\
6.0 \\
5.0 \\
\end{array}$ & $\begin{array}{l}8.0 \\
8.0 \\
8.0 \\
7.0 \\
\end{array}$ & $\begin{array}{l}0.016 \\
0.003 \\
0.001 \\
0.157 \\
\end{array}$ \\
\hline $\begin{array}{l}\text { Academic performance (qualitative) } \\
\text { Outstanding } \\
\text { Merit } \\
\text { Pass } \\
\text { Fail }\end{array}$ & $\begin{array}{l}8.6 \% \\
48.3 \% \\
43.1 \% \\
0.0 \%\end{array}$ & & & & $\begin{array}{l}8.0 \% \\
42.0 \% \\
48.0 \% \\
2.0 \%\end{array}$ & & & & 0.671 \\
\hline
\end{tabular}

Statistics used: T Student to analyze academic performance (quantitative score), Chi-squared to analyze the variable academic performance (qualitative), and Mann-Whitney U statistic for the rest of the variables. 
Figure 1: Flowchart

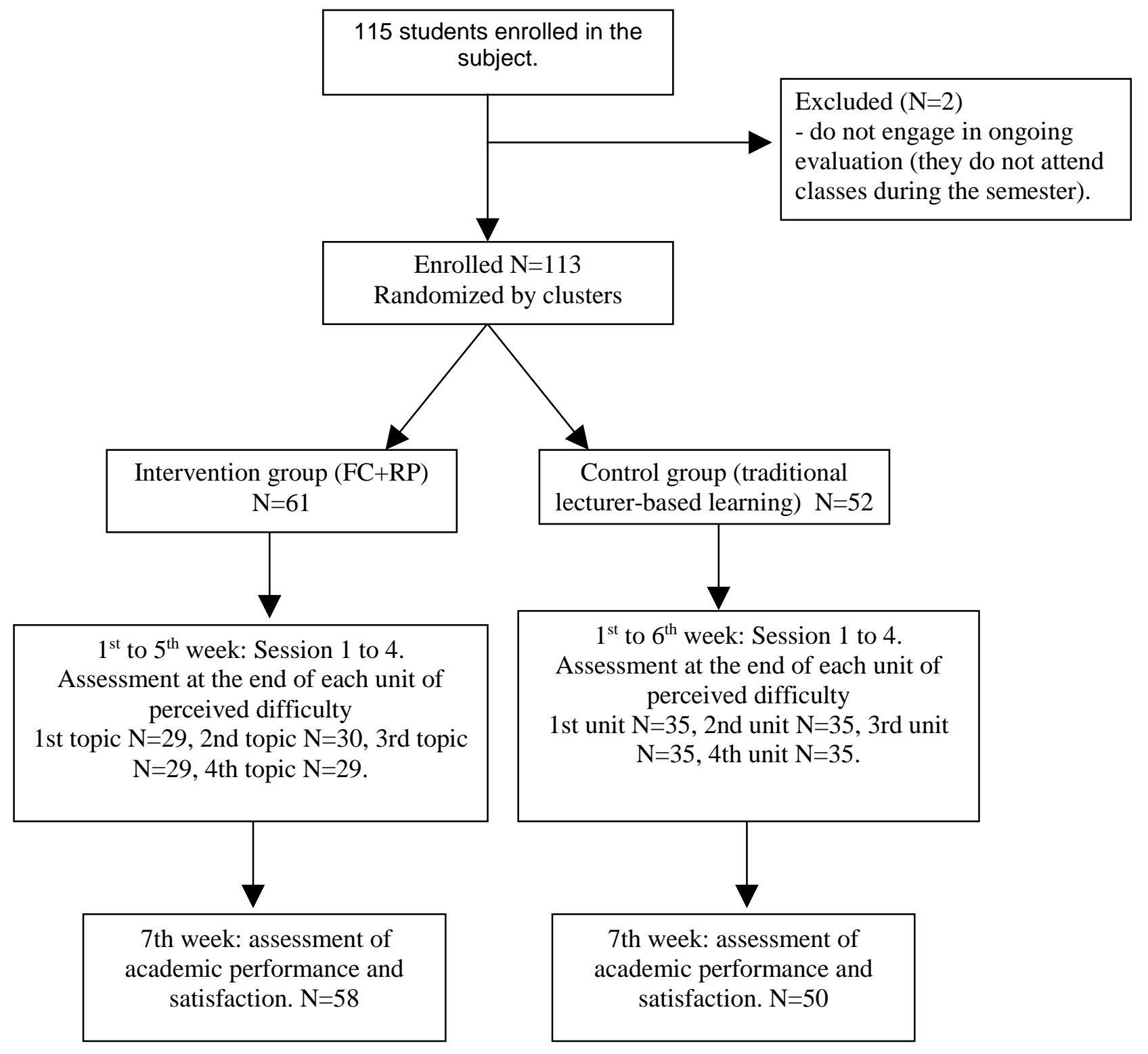

ANALYSIS 